\title{
BMP4 is essential for lens induction in the mouse embryo
}

\author{
Yasuhide Furuta and Brigid L.M. Hogan ${ }^{1}$ \\ Howard Hughes Medical Institute and Department of Cell Biology, Vanderbilt University Medical Center, \\ N ashville, Tennessee 37232-2175 USA
}

\begin{abstract}
Vertebrate lens development is a classical model system for studying embryonic tissue interactions. Little is known, however, about the molecules mediating such inductive events. Here, we show that Bmp4, which is expressed strongly in the optic vesicle and weakly in the surrounding mesenchyme and surface ectoderm, has crucial roles during lens induction. In Bmp4 ${ }^{\mathrm{tm} 1}$ homozygous null mutant embryos, lens induction is absent, but the process can be rescued by exogenous BMP4 protein applied into the optic vesicle in explant cultures. This is associated with rescue of ectodermal expression of Sox2, an early lens placode marker. Substituting the optic vesicle in explant cultures with BMP4-carrying beads, however, does not lead to lens induction, indicating that other factors produced by the optic vesicle are involved. BMP4 appears to regulate expression of a putative downstream gene, Msx2, in the optic vesicle. No change in Pax6 expression is seen in Bmp4 ${ }^{\text {tm1 }}$ mutant eyes, and Bmp4 expression appears unaffected in the eyes of homozygous Pax6 ${ }^{\text {Sey-1N eu }}$, suggesting that PAX6 and BMP4 function independently. Based on these results we propose that BMP4 is required for the optic vesicle to manifest its lens-inducing activity, by regulating downstream genes and/or serving as one component of multiple inductive signals.
\end{abstract}

[Key Words: BM P4; mouse; lens; induction; mutant; explant culture]

Received May 29, 1998; revised version accepted October 2, 1998.

Vertebrate eye development proceeds by a series of reciprocal tissue interactions between derivatives of the head surface ectoderm and the forebrai n neuroectoderm. In particular, the process of lens induction has been studied as a model system to explore general mechanisms underlying embryonic induction (for review, see Jacobson and Sater 1988).

Soon after the turn of this century, a few classical experiments using amphibian embryos led to the idea that the optic vesicle has an instructive role in inducing lens formation in the overlying surface ectoderm (Spemann 1901; Lewis 1904, 1907a,b). According to this original model, the optic vesicle is potentially able to induce a lens from ectoderm anywhere on the embryo. Subsequently, however, other studies using different species and experimental condi tions rai sed doubts about this hypothesis, and rather supported the idea that the optic vesicle is not essential for lens formation (for review, see Saha et al . 1989). Furthermore, a key experiment using a host-donor cell-marking technique revealed that the optic vesicle is insufficient to induce lens in ectopic ectoderm taken from outside the lens field; the induced lens in the recombinants was derived from the optic rudiment, rather than from the grafted ectopic ectoderm (Grainger et al. 1988).

${ }^{1}$ Corresponding author.

E-MAIL brigid.hogen@mcmail.vanderbilt.edu; FAX (615) 343-2033.
The current model, based mainly on experiments using Xenopus embryos, proposes that lens induction proceeds through multiple intermediate states, starting early in development from the gastrula stage (for revi ew, see Grainger 1992). Evidence from many in vivo and in vitro studies indicates that the lens can be formed in the absence of the optic vesicle in several vertebrate species (for review, see Jacobson and Sater 1988; Saha et al . 1989; Henry and Grainger 1990). The role of the optic vesicle during lens induction has, therefore, been considered minor-merely to establish the precise location of the lens within the head ectoderm (Grainger 1992). Several lines of evidence, however, suggest that, in vivo, there is apparent species specificity in the extent to which lens formation is dependent on the optic vesicle. Ablation of prospective retinal neuroectoderm in chick embryos abolishes lens formation ( $\mathrm{Li}$ et al. 1994; Kamachi et al. 1998). Furthermore, lens formation is completely absent in mouse embryos lacking a functional Lhx2 gene, which encodes a LIM-homeodomain protein and is expressed in the forebrain, including the forming optic vesicle neuroectoderm. In these embryos, impairment of optic vesicle development results in failure of the optic vesi cl e to contact the surface ectoderm (Porter et al. 1997). Therefore, it appears that lens formation in higher vertebrates requires the presence of the optic vesicle in vivo.

Like many other embryonic induction processes, se creted signaling molecules are likely to have critical 
roles during lens induction. In spite of the extensive experimental studies in the amphibian system described above, however, no actual signaling molecules have yet been identified. Likewise, al though a number of genes have been implicated in mammalian eye development by molecular and genetic approaches (for review, see Graw 1996; Oliver and Gruss 1997), characterization of their precise in vivo function in many cases awaits further studies. One exception is the Small eye mutant in mouse $\left(\mathrm{Pax}^{\mathrm{Sey}}\right.$ ) and rat ( $(\mathrm{Sey})$, which have been studied extensively in relation to lens induction, as homozygous mutant embryos completely lack lens formation ( $\mathrm{Hill}$ et al. 1991; Matsuo et al. 1993). Mutations in the Pax6 gene, which encodes a paired-type homeodomain protein, have also been associated with congenital eye defects in humans (Jordan et al. 1992; Glaser et al. 1994; Hanson et al. 1994). Tissue recombination experiments using rSey mutant embryos have reveal ed that homozygous mutant ectoderm does not form a lens when recombined with a wild-type optic vesicle, whereas the reciprocal recombination allows lens formation in wild-type ectoderm (Fujiwara et al. 1994). This clearly implies a requirement for PAX6 in the head ectoderm for competence to respond to the optic vesicle signal, and indicates that the optic vesicle retains lens inducing activity in the absence of PAX6 function. The underlying mechanisms of PAX6 function in the ectoderm and inductive signaling factors involved in lens induction are still unknown.

Bone morphogenetic proteins (BM Ps), members of the TGF- $\beta$ superfamily of secretory signaling molecules, have been implicated in many aspects of embryonic tissue interactions (for review, see Hogan 1996). Several BM P family members have been reported to be expressed during mouse eye development (Dudley and Robertson 1997). Furthermore, Bmp7 is required for normal embryonic eye devel opment in the mouse (Dudl ey et al. 1995; Luo et al. 1995). Here, we report that another member of the Bmp gene family, Bmp4, has critical roles during the lens induction process. We show that the optic vesicle is the major source of BM P4 in the early developing eye, and that it is required for lens induction. A series of explant culture experiments suggest that BM P4 is an essential factor to manifest lens inducing activity of the optic vesicle. We al so show that BM P4 regulates specific gene expression in the optic vesicle neuroectoderm. We discuss a model in which BM P4 has multiple roles during mammalian lens induction.

\section{Results}

The optic vesicle is essential for lens formation in the mouse embryo

At early stages of eye development in mouse embryos, contact between the distal part of the optic vesicle and overlying surface ectoderm is establ ished at the 18- to 20-somite stage [9.0 days postcoitum (dpc)] (Fig. 1B). Before this stage, the head mesenchyme is still present between them (Fig. 1A, arrowheads; Kaufman 1994). Formation of the lens placode is first discernible histologi-

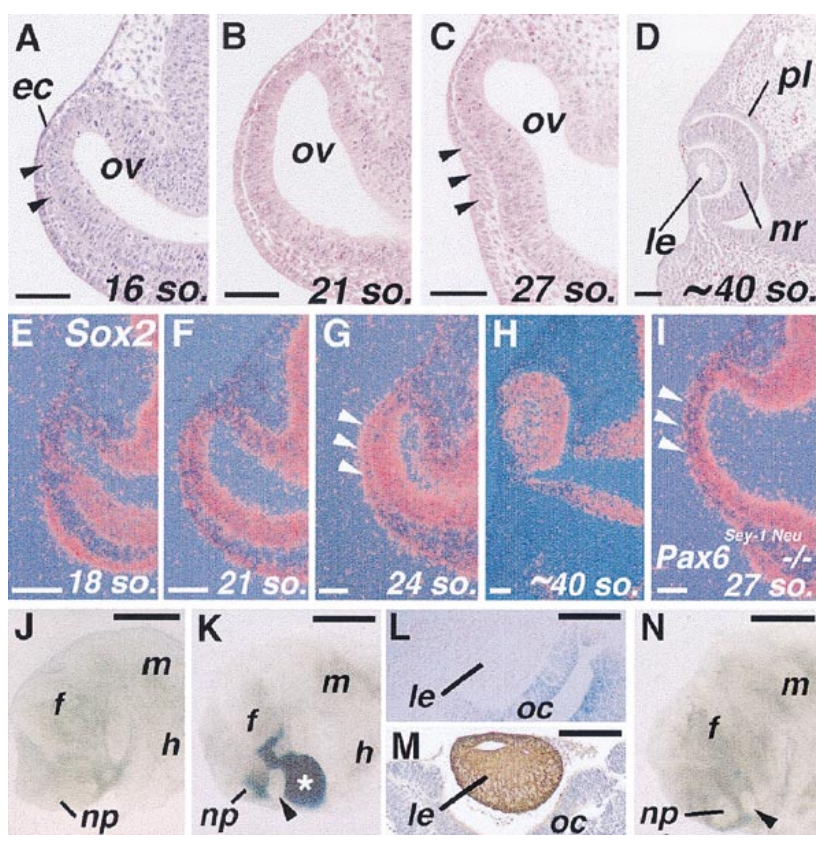

Figure 1. Lens formation in the mouse embryo in vivo and in vitro. (A-D) Frontal sections of the eye primordia from the 16 (16 so.; 8.75-9.0 dpc) to 40-somite stage (10.5 dpc). A rrowheads in (A) indicate head mesenchyme cells that still exist between the ectoderm (ec) and optic vesicle (ov) at this stage, and in C, formation of the lens placode. $(\mathrm{E}-\mathrm{H})$ Expression of Sox2 in the devel oping eye detected by in situ hybridization. Red dots represent hybridization signals, and the blue background illuminates the tissues. Sox 2 is expressed widely in the central nervous system, but its expression in the eye increases only from around $9.0 \mathrm{dpc}(\mathrm{E}, \mathrm{F})$. (G) In the presumptive lens ectoderm, significant upregulation of Sox 2 occurs soon after contact between the ectoderm and optic vesicle (arrowheads), and its expression persists within the lens at later stages $(H)$. (I) In homozygous Pax6 ${ }^{\text {Sey-1Neu }}$ mutant embryos no upregulation of Sox2 expression is observed at stages of lens placode formation. (J-N) Explant cultures of eye primordia of 8.75-9.0 dpc mouse embryos. (J) An explant from an 18-somite-stage embryo cultured for 4 days with the optic vesicle removed. No lens formation is observed. (np) N asal placode; (f) forebrain; (m) midbrain; and (h) hindbrain. (K) Lens formation (arrowhead) in an explant taken from an embryo at the same stage as the one shown in J with the optic vesicle replaced with one from a ROSA26 embryo (asterisk). This allows easy distinction between host- and graft-derived tissues by $\beta$-Gal staining (blue). (L) The rescued lens (le) in such recombinants is derived from host ectoderm (no $\beta$-Gal staining), and $\beta$-Gal staining is present in the grafted optic cup (oc). (M) $\alpha A$-crystall in expression in the lens formed in a recombinant detected by immunohistochemistry (brown). (N) In some explants from 21- to 23-somite-stage embryos with the optic vesile removed, lens formation is observed (arrowhead). In this particular sample, the optic vesicle was replaced with beads (blue dots) to inhibit possible reassociation between the ectoderm and remaining neuroectoderm. The beads have been dislocated by the growth of the lens. (nr) N euroretinal layer of the optic cup; (pl) pigment layer of the optic cup. Bar, $50 \mu \mathrm{m}(\mathrm{A}-\mathrm{l})$; $500 \mu \mathrm{m}(\mathrm{J}, \mathrm{K}, \mathrm{N}) ; 100 \mu \mathrm{m}(\mathrm{L}, \mathrm{M})$.

cally at the 25 - to 27 -somite stage $(9.5 \mathrm{dpc})$ as a slight thickening and invagination of the surface ectoderm at 
the site of contact with the optic vesicle (Fig. 1C; Kaufman 1994). The lens determination process, however, which should precede any morphologi cal manifestations in the surface ectoderm, has not been well characterized in the mouse. For example, it is not known when the final specification of the ectoderm to a lens fate occurs.

To begin to address this question, we studied in detail the expression of Sox2, a member of the HMG box-containing genefami ly implicated in early lens development (Kamachi et al. 1995; Kamachi et al . 1998). Expression of Sox2 in the eye primordium is detected by in situ hybridization at only slightly above background levels until the 18-somite stage (Fig. 1E), and is then gradually upregulated in the optic vesicle and, to a lesser extent, also in the ectoderm as development proceeds (Fig. 1F). At the 23- to 24-somite stage, expression of Sox2 is significantly upregulated in the presumptive lens ectoderm at the site of contact with the optic vesicle (Fig. 1G, arrowheads). Its expression persists in the lens at later stages until around $11.5 \mathrm{dpc}$ (Fig. 1H; Kamachi et al. 1998). Therefore, upregulation of Sox 2 in the lens ectoderm appears to occur a few hours earlier than when the lens placode is first histologically discernible. Furthermore, Sox2 fails to be upregulated in the ectoderm of

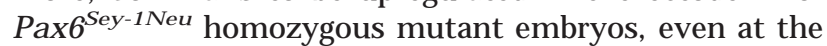
27-somite stage (9.5-9.75 dpc) (Fig. 1I). Because lens induction is defective in these embryos, this result supports the notion that upregulation of Sox 2 is tightly associated with induction of the lens placode.

To determine more di rectly when the head surface ectoderm is specified to a lens fate, explants of one side of the head containing the entire eye field isolated from embryos between 8.5 and $9.0 \mathrm{dpc}$ were cultured intact or with the optic vesicle removed (Table 1) (for convenience, we refer to this type of explants as eye primordia). Under the conditions employed, almost all of the unmanipulated eye primordia from the 14-somite stage or later embryos form distinct lenses after 2-4 days of culture (see Fig. 4A,B below). When the optic vesicle is excised from primordia at the 14- to 20-somite-stages,

Table 1. Explant cultures of mouse embryonic eye primordia (4-day culture)

\begin{tabular}{|c|c|c|c|c|}
\hline $\begin{array}{l}\text { Stage } \\
\text { (somites) }\end{array}$ & $\begin{array}{l}\text { Type of } \\
\text { operation }\end{array}$ & $\begin{array}{c}\text { No. of } \\
\text { samples } \\
\text { examined }\end{array}$ & $\begin{array}{l}\text { Lens } \\
\text { formation } \\
(\%)\end{array}$ & $\begin{array}{c}\text { Relative } \\
\text { lens } \\
\text { size }^{a}\end{array}$ \\
\hline $10-13$ & - & 15 & $0(0)$ & - \\
\hline $14-17$ & - & 56 & $52(93)$ & $+H$ \\
\hline $18-20$ & - & 59 & 59 (100) & $H+$ \\
\hline $21-23$ & - & 34 & 34 (100) & $+1+$ \\
\hline $14-17$ & o.v. removed & 30 & $0(0)$ & - \\
\hline $18-20$ & o.v. removed & 48 & $0(0)$ & - \\
\hline $14-20$ & $\begin{array}{l}\text { o.v. replaced with } \\
\text { ROSA } 26 \text { o.v. }\end{array}$ & 38 & $33(87)$ & + to ++ \\
\hline $21-23$ & o.v. removed & 96 & $9(9)$ & + to $+1+$ \\
\hline
\end{tabular}

a Category of lens sizes: (+H) Comparable to unmanipulated controls; (+) approximately half the size of controls or larger; ( + ) lentoid or smaller than half the size of control.

(o.v.) Optic vesicle. lens formation is never observed, although the tissues continue to grow (Fig. 1); Table 1). Expression of Sox2 is also not observed in the ectoderm of this explant group when assayed at $18 \mathrm{hr}$, and 2 and 4 days (data not shown). Control experiments show that if the optic vesicle is removed but then immediately replaced, lens formation is rescued in nearly $90 \%$ of the explants (Fig. 1K-M; Table 1). In contrast, substituting the optic vesicle with neuroectoderm from other regions of the brain cannot induce lens (see Table 3 below). These results suggest that the optic vesicle is essential for lens induction in the overlying surface ectoderm. When the optic vesicle is removed from eye primordia of 21- to 23-somite-stage embryos, however, lens formation occurs in $~ 9 \%$ of the cases (Table 1; Fig. 1N). This may represent lens formation in advanced embryos within this group, and there fore, the optic vesicle becomes dispensable after around the 23-somite stage. This stage is consistent with the upregulation of Sox2 in the presumptive lens ectoderm in normal development.

Bmp4 and its receptor genes are expressed in the early developing eye

Previous studies showed that Bmp7 is essential for mouse eye development (Dudley et al. 1995; Luo et al. 1995). Several other members of the Bmp gene family are also expressed during mouse eye development (Dudley and Robertson 1997). In this study, we have focused on one of these members, Bmp4. Detailed in-situ hybridization analyses reveal that Bmp4 transcripts are present before, and following, lens placode formation (Fig. 2). At the 8- to 12-somite-stage, when the optic vesicle begins to form as a bilateral evagination of the forebrain neuroectoderm, Bmp4 mRNA cannot be detected in the eye region (Fig. 2A). Expression of Bmp4 is first observed in the distal part of the forming optic vesicle and the overlying surface ectoderm at the 14- to 16-somite-stage (Fig. 2B, arrowheads). As development proceeds, the level of Bmp4 expression is gradually increased in the distal optic vesicle (Fig. $2 \mathrm{C}, \mathrm{D}$ ). Toward the stage of Iens placode formation, expression of Bmp4 becomes restricted to the dorsal tip of the optic vesicle and no longer detected in the lens placode (Fig. 2E). At later stages, high levels of transcripts are maintained in the dorsal margin of the optic cup (Fig. 2F). Throughout these stages, Bmp4 is al so expressed in the ectoderm of the nasal-oral region, just ventral to the lens ectoderm (Fig. 2D-F).

Two type-I BMP receptors, which bind to BMP4 in vitro (ten Dijke et al. 1994), are also expressed in the developing eye. Expression of Alk3 (BmprlA) is almost ubi quitous from early stages of devel opment, both in the embryo as a whole (Dewulf et al. 1995; Mishina et al. 1995) and in the eye until 10.5-11.5 dpc (Fig. 2G-J, and data not shown). In contrast, significant levels of Alk6 (BmprlB) transcripts are detected only from around the 16-somite stage in a part of the future retina and optic stalk region (Fig. 2L-O). The domain of Alk6 expression appears to define a region complementary to that of Bmp4 within the neuroretina (Fig. 2E,F and N ,O) Expres- 


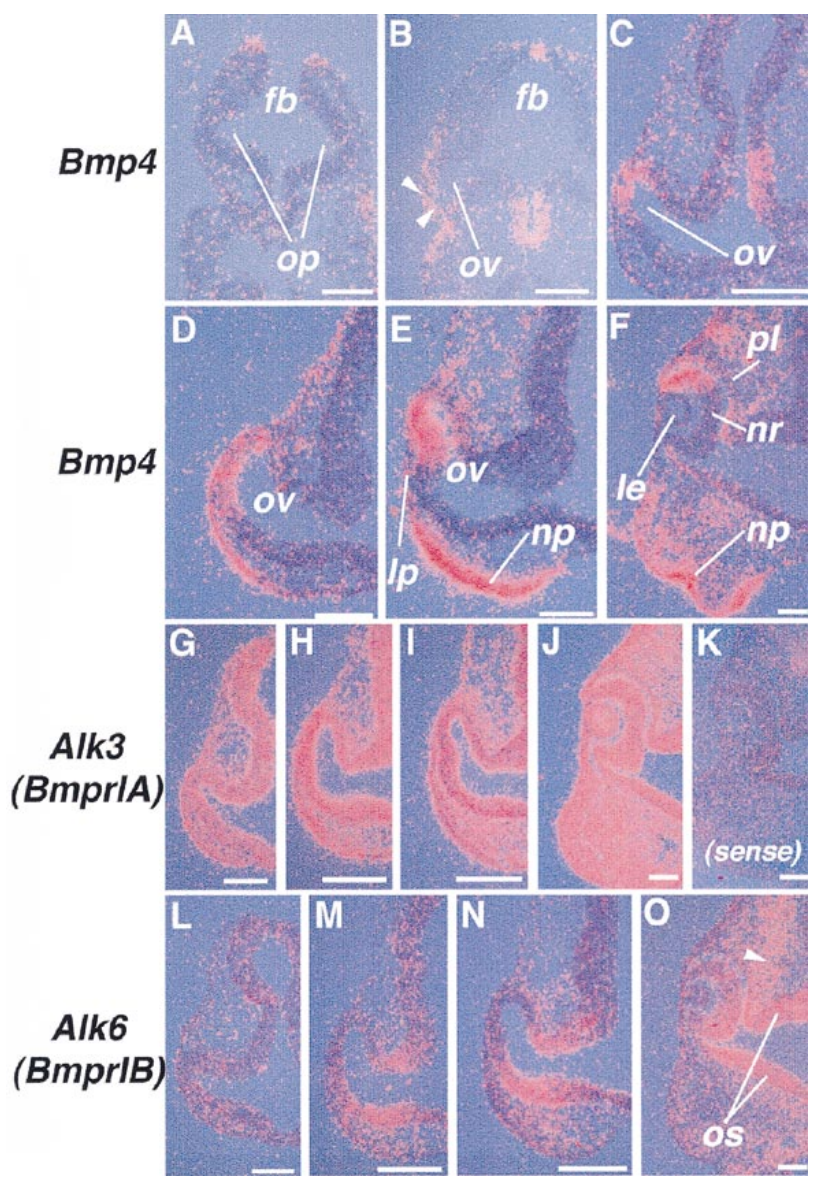

Figure 2. Expression of Bmp4 and BMP type-l receptor genes during early eye development. (A-F) In situ hybridization using an antisense riboprobe for Bmp4 on transverse sections of 10(A) and 14- (B) somite-stage embryos, and on frontal sections of 18- (C), 22- (D), 27- (E), and 40-somite-stage (10.5 dpc) (F) embryos. Arrowheads in B indicate early Bmp4 expression both in the ectoderm and distal optic vesicle. (G-O) In situ hybridization for BMP type-l receptor genes on frontal sections of embryos at the $18-(\mathrm{G}, \mathrm{L}), 22-(\mathrm{H}, \mathrm{M}), 26-(\mathrm{I}, \mathrm{N})$, and 40 -somite stages $(10.5 \mathrm{dpc})(\mathrm{J}, \mathrm{O})$. A rrowhead in $\mathrm{O}$ shows expression of Alk6 (BmprlB) in the neural crest mesenchyme. Hybridization with a sense control probe for Alk3 gives signals only at background levels in a section of a 10.5 dpc embryo (K). (Ip) Lens placode; (op) optic pit; (os) optic stalk. Bar, $50 \mu \mathrm{m}$.

sion of Alk6 is seen also in the head mesenchyme, presumably of neural crest origin, from $9.5 \mathrm{dpc}$ (Fig. $2 \mathrm{~N}, \mathrm{O}$ ).

Defective lens induction in $\mathrm{Bmp} 4^{\mathrm{tm} 1}$ homozygous null-mutant embryos

The expression patterns of Bmp4 and Bmpr genes led us to analyze the eye phenotype of $\mathrm{Bmp} 4^{\mathrm{tm} 1}$ homozygous mutant embryos. Although most of these mutants arrest development at gastrulation or later with severe deficits of posterior mesodermal structures, such as the allantois, we have found that on a mixed genetic background (see Materials and Methods) $30 \%$ exhibit milder phe- notypes, surviving until $10.5 \mathrm{dpc}$. At this time, they form 20-27 somites, whereas the normal littermates have more than 35 . These late surviving homozygous mutant embryos were first examined histologically. Despite close contact between the surface ectoderm and optic vesicle, no indication of lens placode formation is observed (Fig. 3B,C), although the nasal placode is developed in the adjacent regi on of the ectoderm (Fig. 3C). In none of these advanced mutant embryos (23-25 somites) is upregulation of Sox 2 detected in the prospective lens ectoderm (Fig. 3D,H). In contrast, expression of Pax6 and Six3, which are the mammalian homologs of key regulators of Drosophila eye development (for review, see Oliver and Gruss 1997), appears to be unaffected (Fig. $3 E, F, I, J)$, suggesting a defect in a late phase of lens determination. Expression of Bmp7 also appears to be unaffected (Fig. 3G,K).

To determine whether lack of lens formation in the mutants is attri butabl e to a general devel opmental delay, eye primordia from advanced mutant embryos were cultured in vitro. After 2-4 days, wild-type eye primordia

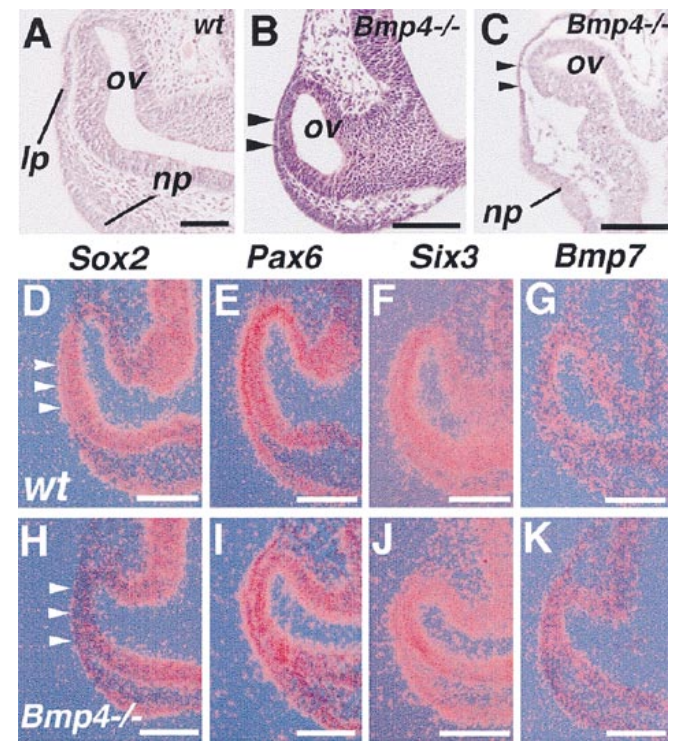

Figure 3. Eye phenotypes of late surviving $B m p 4^{\text {tm1 } 1}$ homozygous mutant embryos. (A) Morphology of the normal eye of a 27-somite-stage embryo (9.75 dpc). (ov) Optic vesicle; (Ip) lens placode; and (np) nasal placode. (B) Histological section of a mutant embryo with 25 somites at $10.0 \mathrm{dpc}$. No sign of lens placode formation is seen at the site of contact between the ectoderm and the optic vesicle (arrowheads). (C) A nother mutant embryo at $10.5 \mathrm{dpc}$ showing no lens placode formation (arrowheads). N ote that the nasal placode is formed. (D-K) Gene expression in the eyes of 22- to 24-somite-stage wild-type (wt) (D-G), and 9.5-10.0 dpc homozygous Bmp4 ${ }^{\mathrm{tm} 1}$ mutant embryos $\left(\mathrm{Bmp4}^{-1-}\right)$ which formed $22-25$ somites $(\mathrm{H}-\mathrm{K})$. N ote that, although upregulated in the wild-type presumptive lens ectoderm by the 24-somite stage ( $D$, arrowheads), Sox 2 fails to be induced in the mutant ectoderm and the optic vesicle $(H)$. (E-G, I-K) Expression of other putative regulatory genes, including Pax6 $(E, I)$, Six3 $(F, J)$, and Bmp7 $(G, K)$ is not apparently changed. Each panel is representative of results from at least three wild-type or five mutant embryos. Bar, $100 \mu \mathrm{m}(A-C) ; 50 \mu \mathrm{m}(D-K)$. 
form distinct eye structures including the lens, retina, and pigmented epithelium (Fig. 4A,B). In contrast, when mutant eyes are cultured, although the explants grow significantly in size, 3-4 times in di ameter, and some of them produce pigment, lens formation is never observed macroscopi cally even after 4-5 days (Fig. 4C and data not shown; Table 2). Histological examination confirms complete absence of lens devel opment in these explants (Fig. 4D, arrowheads). These in-vitro observations suggest that mutant eye tissues survive under these culture conditions, but that lens formation does not occur. This provides further evidence that lens induction is defective in Bmp4 ${ }^{\mathrm{tm} 1}$ mutant embryos.

Rescue of lens formation by exogenous BMP4 protein in mutant eye explants

To test the requirement for BM P4 in lens induction more directly, we examined whether lens formation in the $\mathrm{Bmp} 4^{\mathrm{tm} 1}$ mutant eye could be rescued with recombinant BMP4 protein (Table 2). Because high levels of Bmp4 transcripts are normally present in the optic vesicle, BM P4 protein was applied, using protein-carrying beads loaded into the optic vesicle. Development of the wildtype eye explants appears to be unaffected by application of BMP4-carrying beads, compared with the explants from the contra-lateral side cultured with control beads (Table 2). When eye primordia from advanced Bmp4 ${ }^{\mathrm{tm} 1}$ mutants at 9.5-10.0 dpc are cultured with BM P4 beads (Fig 5A, arrowheads), single lens-like vesi cul ar structures are observed in the explants after 3-4 days of culture (Fig. 5A, arrow; Table 2). Histological examination shows that these vesicular structures are derived from the ec-

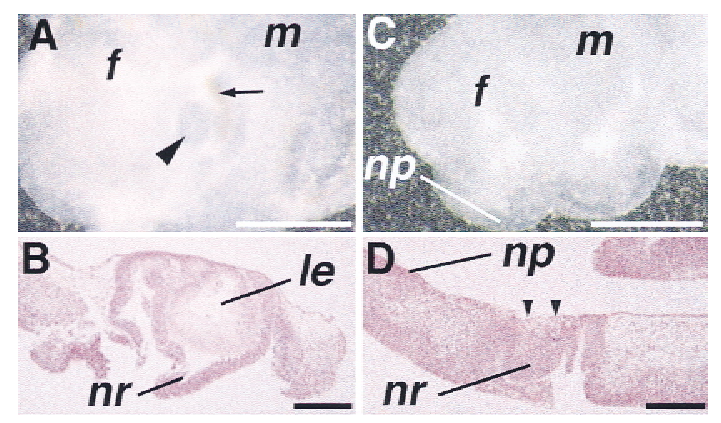

Figure 4. M orphology of eye explants in vitro. (A) A wild-type eye primordium taken at the 20-somite stage and cultured for 4 days. $\mathrm{N}$ ot only the lens (arrowhead) but al so surrounding retina and pigmented epithelium (arrow) are easily recognized under the dissection microscope. (B) Histological section of the eye explant shown in A. A well-differentiated lens (le) is seen, surrounded by the neuroretina (nr) of the optic cup. (C) An eye primordium from a 9.5-dpc mutant embryo cultured for 5 days. $\mathrm{N}$ o lens formation is recognized macroscopically. (D) Histological section reveals that the lens is absent in the mutant eye primordium at the site of contact between the ectoderm and prospective neuroretina (arrowheads), whereas the nasal placode (np) is developed in the adjacent ectoderm. Bar, $500 \mu \mathrm{m}$ $(A, C) ; 100 \mu m(B, D)$. toderm (Fig. 5B), and express Pax6 (Fig. 5C). Furthermore, these vesicles stain positively with an anti body for $\alpha A$-crystallin (Fig. 5D). N o rescue of lens formation has ever been observed in mutant samples taken from the contra-lateral side and cultured with control beads (Table 2). Upregulation of Sox2 is seen in the surface ectoderm after 1-2 days of culture with BM P4 beads (Fig. $5 \mathrm{E}$, arrowheads) $(\mathrm{n}=6)$, and persists later in the rescued lens (data not shown). In contrast, in the control samples, expression of Sox2 is not induced in the ectoderm during the culture period (Fig. 5F, arrowheads) $(n=6)$. High levels of Sox2 transcripts are induced in the optic vesicle of both BM P4-treated and control samples, suggesting expression of this gene in the optic vesicle is independent of BMP4 activity (Fig. 5E,F). These results demonstrate that lens induction in the $B m p 4^{\mathrm{tm} 1}$ mutant eye can be restored by application of exogenous BM P4.

BMP4 is not sufficient to substitute

for the lens-inducing activity of the optic vesicle

The in situ hybridization results suggest that the optic vesicle is the major source of BM P4 in the devel oping eye (Fig. 2). To test whether BM P4 acts directly as the lens inducing signal to the ectoderm, the optic vesicle was replaced with beads carrying BMP4 protein (Table 3). These experiments were performed using eye tissues from 16- to 20-somite-stage wild-type embryos, as formation of the lens is still dependent on the optic vesicle at these stages (see above; Fig. 1J and Table 1). Removal of the optic vesicle followed by implantation of BM P4 beads does not, however, induce lens in these explants (Table 3). In addition, no upregulation of Sox 2 in the prospective lens ectoderm is seen after $18 \mathrm{hr}$, and 2 or 4 days of culture (data not shown). We al so tested whether other embryonic tissues expressing BM P4 can induce a lens when substituted for the optic vesicle in culture. We have observed no lens formation using dorsal forebrain neuroectoderm or heart which express high levels of Bmp4 (Dudley and Robertson 1997; Furuta et al. 1997) (Table 3). These results suggest that BMP4 alone or Bmp4-expressing tissues other than the optic vesicle are not sufficient to induce a lens, and therefore cannot substitute for the lens inductive activity of the optic vesicle.

Bmp4 regulates specific gene expression in the optic vesicle neuroectoderm

One of the possibilities is that BMP4 regulates lens inductive activity by inducing downstream gene(s)/factor(s) in the optic vesicle. To examine this, we have taken a candidate gene approach. Among the genes potentially downstream of BM P-type signals in various devel opmental systems (for review, see Hogan 1996), members of the M sx gene family have been implicated in eye devel opment (M onaghan et al. 1991). One member of the Msx gene family, Msx2, is normally expressed in the optic vesicle and the overlying surface ectoderm before lens 
Table 2. Rescue of lens formation in $\mathrm{Bmp} 4^{\mathrm{tm} 1}$ mutant eye primordia by beads carrying BMP4 protein (4- to 6-day culture)

\begin{tabular}{|c|c|c|c|c|}
\hline $\begin{array}{l}\text { Genotype } \\
\text { and } \\
\text { stage }\end{array}$ & $\begin{array}{l}\text { Type of beads } \\
\text { transplanted } \\
\text { into o.v. }\end{array}$ & $\begin{array}{c}\text { No. of samples } \\
\text { examined }\end{array}$ & $\begin{array}{l}\text { Lens } \\
\text { formation (\%) }\end{array}$ & Relative lens size ${ }^{a}$ \\
\hline Bmp4-1- day 9.5-9.75 & no bead & 14 & $0(0)$ & - \\
\hline Wild type $14-20$ somite & BMP4 & 27 & $27(100)$ & Hto +1 \\
\hline Wild type $14-20$ somite & BSA & 27 & $27(100)$ & H to ++ \\
\hline Bmp4 $4^{-1}$ day $9.5-9.75$ & BM P4 & 58 & $35(60)$ & + \\
\hline Bmp4 ${ }^{-1-}$ day $9.5-9.75$ & BSA & 58 & $0(0)$ & - \\
\hline
\end{tabular}

${ }^{a}$ Category of lens sizes: (++) Comparable to unmanipulated controls; (+) approximately half the size of controls or larger; (+) lentoid or smaller than half the size of control.

(o.v.) Optic vesicle.

induction (Fig. 6A; Monaghan et al. 1991), in a pattern similar to that of Bmp4. In contrast, in Bmp4 ${ }^{\mathrm{tm} 1}$ mutant embryos expression of Msx2 is not detected in the eye regi on (Fig. 6B), whereas expression in other regi ons such as in the branchial arches appears unaffected (not shown). M oreover, Msx2 expression is rescued in mutant eye explants cultured with BMP4-carrying beads (Fig. $6 C)(n=4)$. In the contra-lateral side of the eye tissues

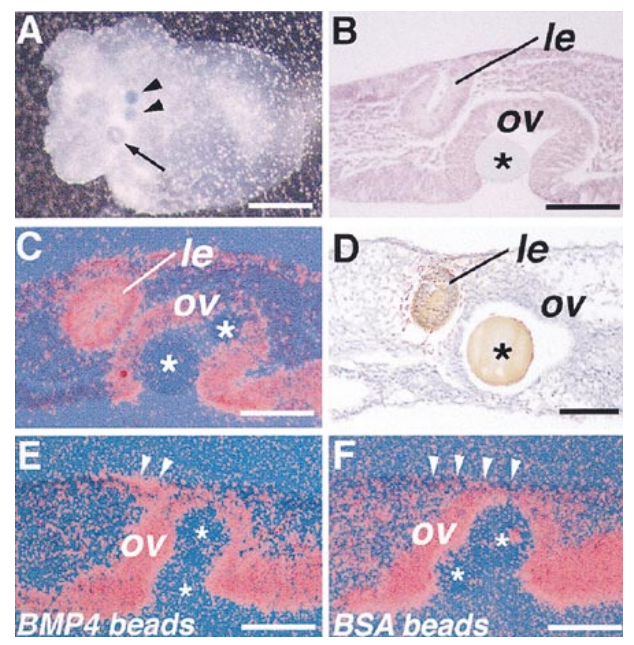

Figure 5. Rescue of lens formation in explant cultures of $\mathrm{Bmp}^{\mathrm{tm} 1}$ mutant eyes. (A) A mutant eye primordium cultured with BM P4-carrying beads (arrowheads) in the optic vesicle after 4 days of culture. A single vesicular structure is found macroscopically (arrow). (B) Histological section of the explant shown in $A$. The vesicular structure is a lens (le) derived from the ectoderm. (C) Pax6 is expressed in the formed lens vesicle. (D) $\alpha A$-crystallin expression within the vesicle (arrowheads) detected by immunohistochemistry, confirming differentiation of lens cells. (E,F) Expression of Sox 2 in mutant eye explants cultured for 1 day. (E) Sox 2 is induced in both the surface ectoderm (arrowheads) and the optic vesicle of explants cultured with BM P4-carrying beads. (F) In contrast, although activated in the optic vesicle, expression of Sox 2 is not detected in the ectoderm of the lens region (arrowheads) in the explants cultured with control BSA beads. Asterisks indicate the beads transplanted into the optic vesicle (ov). Bar, $250 \mu \mathrm{m}$ (A); $50 \mu \mathrm{m}$ (B-F). cultured with control beads, Msx2 expression is not detected above background levels during culture periods of up to 6 days (Fig. 6D) $(n=4)$. These data demonstrate that expression of Msx2 depends on BM P4 activity in the optic vesicle, and therefore BM P4 functions to regulate specific gene expression within the optic vesicle.

Tissue recombination between $\mathrm{Bmp} 4^{\mathrm{tm} 1}$ mutant and wild-type eye components

To further investigate the mechanisms by which BM P4 partici pate in lens induction, we generated recombinant explants between wild-type and mutant tissues by combining an optic rudiment (optic vesicle and mesenchyme) with ectoderm. To distinguish the origin of tissues in the recombinant explants, we obtained wild-type samples from embryos of the ROSA26 mouse strain. In recombinations between wild-type optic rudiments and either wild-type or mutant ectoderm, the lens forms consistently after 3-4 days of culture (Fig. 7A-D and Table 4). We next tested the combination between wild-type ectoderm and mutant optic rudiments. In these experiments, we have al so observed invagi nation of the surface ectoderm, though at a low frequency (Table 4). Although these lentoid structures are often irregular in morphology compared to those in other types of recombinations (Fig. 7, cf. E with A and C), they are associated with the retinal neuroectoderm which forms an optic cup (Fig. $7 E$ ), and express $\alpha A$-crystallin (Fig. 7F). In this type of recombination, BMP4 is not produced in the optic

Table 3. Bead and tissue transplantations using eye primordia of 16- to 20-somite stage wild-type embryos (4-day culture)

\begin{tabular}{lcc}
\hline $\begin{array}{l}\text { Type of operation } \\
\text { (o.v. replaced with) }\end{array}$ & $\begin{array}{c}\text { N o. of samples } \\
\text { examined }\end{array}$ & $\begin{array}{c}\text { Lens formation } \\
(\%)\end{array}$ \\
\hline BSA beads & 23 & $0(0)$ \\
BM P4 beads & 57 & $0(0)$ \\
Day 10.0 dorsal & 9 & $0(0)$ \\
$\quad$ forebrain & 5 & $0(0)$ \\
\hline
\end{tabular}

(o.v.) Optic vesicle. 


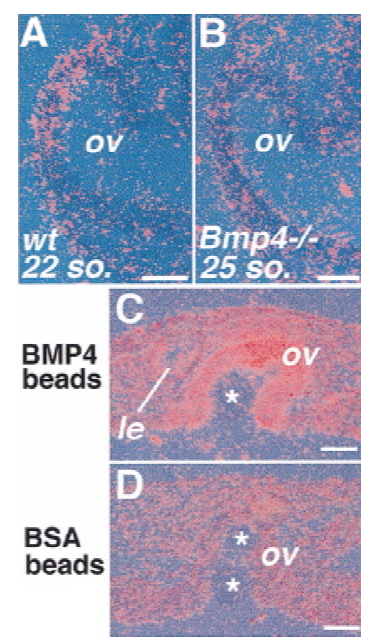

Figure 6. Expression of Msx2 in the eye. (A) Msx2 is weakly expressed by the 22-somite stage in normal embryos. (B) In the eye of advanced mutants, Msx2 expression is not detected even at the 25-somite stage or later ( $n=9$ ). (C) A pplication of BM P4 in the mutant optic vesicle induces Msx2, and its expression is maintained after 4 days of culture. (D) In mutant explants with control beads, Msx2 expression is never detected throughout the culture period. Asterisks indicate implanted beads. (le) Rescued lens. Bar, $50 \mu \mathrm{m}(\mathrm{A}, \mathrm{B}) ; 25 \mu \mathrm{m}(\mathrm{C}, \mathrm{D})$.

vesicle and surrounding mesenchyme. By the time of recombination, however, the wild-type ectoderm is likely to have been exposed to BM P4 and/or BM P4-dependent signals emanating both from itself and/or the underlying optic vesicle. These results indicate that even in the absence of BM P4 in the optic rudiment, lens formation can be initiated if the ectoderm has been exposed previously to BMP4. We speculate that additional factor(s) that emerge from the optic vesicle are required for lens induction in concert with BMP4 expressed in the optic vesicle and the surface ectoderm (see Discussion).

Expression of Bmp4 and its receptor genes in the Pax6 $6^{\mathrm{Sey}-1 \mathrm{~N} \text { eu }}$ homozygous mutant eye

Tissue recombination experiments using rSey mutant embryos demonstrated that Pax 6 function is required in the surface ectoderm to respond to the lens inductive signal (Fuji wara et al. 1994). To test the possibility that Pax6 regulates expression of Bmp4 and its receptor genes, we examined the expression of these genes in Pax6 ${ }^{\text {Sey-1Neu }}$ homozygous mutant embryos around the time of lens induction. We observed no drastic change in the expression patterns of Bmp4, Alk3, and Alk6 in the eye region (Fig. $8 \mathrm{~A}-\mathrm{C}$; cf. with Fig. 2D,H,M ). Because in homozygous Bmp4 mutant embryos Pax6 is normally expressed both in the ectoderm and the optic vesicle, expression of Pax6 and Bmp4 appear to be regulated and to function independently of each other during lens induction.

\section{Discussion}

The optic vesicle has a critical role as a source of inductive signal for lens determination in higher vertebrates

We have shown using explant cultures of embryonic eye primordia that the optic vesicle has a critical role in lens induction in the mouse. These results are consistent with the in vivo observations reported previously for chick and mouse embryos (Li et al. 1994; Porter et al. 1997; Kamachi et al. 1998). Therefore, the optic vesicle appears to provide an essential local inductive cue for lens induction in vivo in higher vertebrates.

During normal eye development, soon after the surface ectoderm meets the optic vesicle, expression of Sox 2 is upregulated in the ectoderm at the site of contact, and this precedes lens placode formation (Fig. 1G). Such upregulation of Sox 2 is, however, not observed in the presumptive lens ectoderm of homozygous Pax6 $6^{\text {Sey-1Neu }}$ mutant embryos that lack lens induction, suggesting that expression of Sox 2 is tightly associated with lens

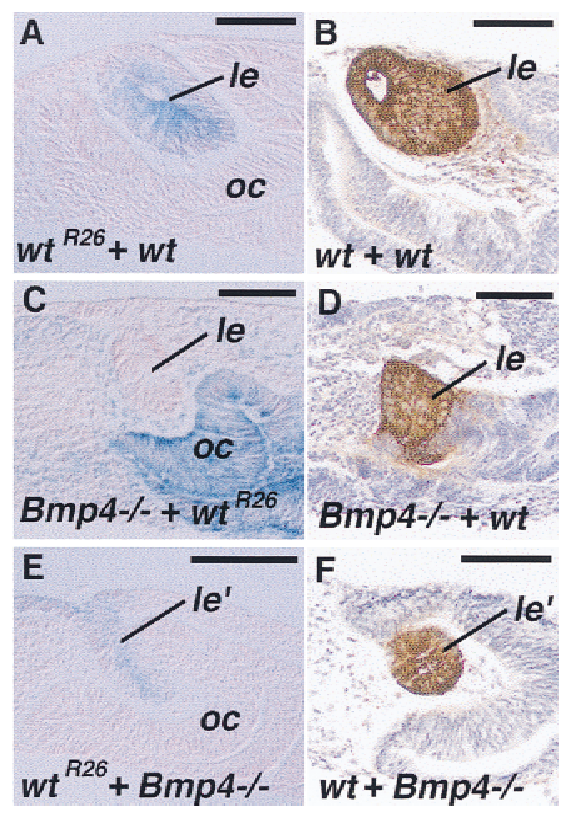

Figure 7. Tissue recombination explants between wild-type (wt) and Bmp4 ${ }^{\mathrm{tm} 1}$ mutant (Bmp4 $\left.4^{-1}\right)$ eye tissues after 4-day culture. Wild-type tissues from the ROSA26 strain of mouse $\left(w t^{R 26}\right)$ are revealed by blue $\beta-G$ al staining in $(A, C, E)$. (A) $R e-$ combinant between wild-type ectoderm $\left(w^{R 26}\right)$ and optic rudiment (optic vesicle and surrounding mesenchyme). Formation of a relatively normal sized lens (le) is observed (blue staining), associated with formation of the optic cup (oc). (B) $\alpha$ A-crystallin expression in a wild-type-wild-type recombinant (brown). (C) Lens formation is also found in the mutant ectoderm when recombined with a wild-type optic rudiment. (D) Expression of $\alpha \mathrm{A}$-crystallin in such $\mathrm{Bmp4}^{-1-}$-wild-type recombinants. (E) Formation of the lentoid $\left(\mathrm{Ie}^{\prime}\right)$ in a recombinant between a wild-type ectoderm and $\mathrm{Bmp} 4^{-1-}$ optic rudiment. Such lentoids are often irregular in shape, but are surrounded by the retinal neuroectoderm, which forms an optic cup (oc). (F) Such lentoids are positive for $\alpha$ A-crystallin. Bar, $50 \mu \mathrm{m}$. 
Table 4. Tissue recombination experiments between wild-type (16- to 20-somite stage) and Bmp ${ }^{4 t m 1}$ homozygous mutant eye primordia (4-day culture)

\begin{tabular}{llccc}
\hline Ectoderm & $\begin{array}{c}\text { Optic rudiment } \\
\text { (optic vesicle and } \\
\text { mesenchyme) }\end{array}$ & $\begin{array}{c}\text { No. of samples } \\
\text { examined }\end{array}$ & $\begin{array}{c}\text { Lens } \\
\text { formation (\%) }\end{array}$ & $\begin{array}{c}\text { Relative lens } \\
\text { size }\end{array}$ \\
\hline Wild type (ROSA26) & wild type & 17 & $9(100)$ & + to ++t \\
Bmp4 ${ }^{-1}$ day 9.75-10 & wild type (ROSA26) & 14 & $5(25)$ & + to ++ \\
Wild type (ROSA26) & Bmp4-1-day 9.75-10 & 20 & +to + & b \\
\hline
\end{tabular}

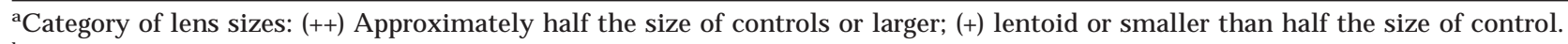

bM orphology of the lentoids is irregular.

determination in the ectoderm (Fig. 11). Furthermore, in our explant cultures, Sox 2 fails to be induced in the presumptive lens ectoderm if the optic vesicle is removed as early as the 20-somite stage, and lens induction is never observed. Therefore, el evation of Sox 2 expression in the lens ectoderm appear to require an induction from the optic vesicle by this stage. These results are consistent with the recent study by Kamachi et al . using chick embryos, showing that expression of Sox2 and Sox3 requires induction from the optic vesicle (Kamachi et al. 1998).

BMP4 is required for the lens inductive activity of the optic vesicle

We have provided here genetic evidence that BMP4 is essential for lens induction in the mouse. In advanced $\mathrm{Bmp} 4^{\mathrm{tm} 1}$ homozygous mutant embryos, despite contact between the ectoderm and optic vesicle neither lens placode nor expression of Sox 2 is induced in the prospective lens ectoderm (Fig. 3B,C,H). Formation of the Bmp4 mutant optic vesicle appears relatively normal, based on the expression of several putative regulatory genes such as Pax6, Six3, Bmp7 (Fig. 4), and Bf1 and Bf2, Eyal and Eya2, and Otx2 (data not shown). We conclude, therefore, BMP4 may be required for the final phase of lens determination in the head surface ectoderm.

We have also shown that lens formation in mutant embryos can be rescued by application of beads soaked with BMP4 inside the optic vesicle. In these explants,

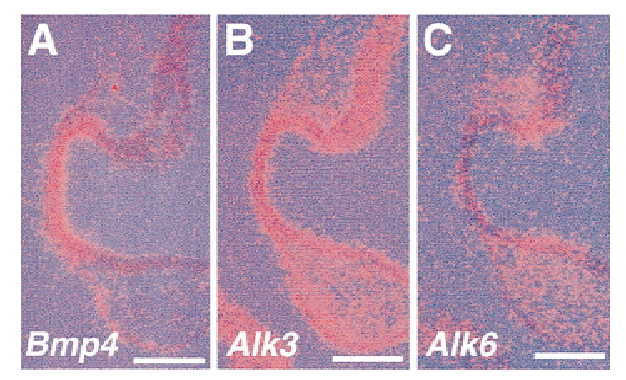

Figure 8. Expression of genes for BMP4 and its receptors in Pax6 $6^{\text {Sey-1Neu }}$ homozygous mutant eyes. Expression of Bmp4 (A), Alk3 (B), and Alk6 (C) in 21-somite-stage mutant embryos is essentially localized to the appropriate areas compared with normal embryos (see Fig. 2D,H,M ). Bar, $50 \mu \mathrm{m}$. expression of Sox 2 in the ectoderm is observed after 1 day in culture (Fig. 5E). In contrast, Sox2 is not upregulated in the presumptive lens ectoderm in explants with control beads (Fig. 5F). These results suggest that BM P4 is critical for the ability of the optic vesicle to induce high levels of Sox2 expression in the ectoderm, and later, to induce lens.

BMP4 may manifest lens inductive activity in the optic vesicle neuroectoderm

Based on its expression pattern (Fig. 2), it is possible that BMP4 functions as an optic vesicle-derived signal re quired for determining the lens ectoderm. Replacement of the optic vesicle in the wild-type eye primordium with BM P4-soaked beads or other Bmp4 expressing tissues does not induce lens formation (Table 3 ) or Sox2 expression in the ectoderm (data not shown). This indicates that BM P4 al one is not sufficient to mi mic the lens inductive activity of the optic vesicle.

One possible function of BM P4 during this process is to induce within the optic vesicle the expression of downstream molecul e(s) that function as the lens inductive signal (Fig. 9). We show that expression of Msx2, which is detected in the developing mouse eye (Monaghan et al. 1991), is missing in the eye of Bmp4 ${ }^{\mathrm{tm1}} \mathrm{mu}-$ tant embryos (Fig. 6A,B). Furthermore, its expression can be induced by the addition of BMP4 protein into the Bmp4 mutant eye tissue (Fig. 6C). Induction of Msx2 is specific, as control beads cannot induce expression of this gene (Fig. 6D). In contrast, Sox 2 is switched on in the optic vesicle independently of BM P4 activity (Fig. 5E,F), excluding the possibility that lack of Msx2 expression and lens induction is due to a nonspecific delay in the developmental program of the mutant eye. The functional significance of Msx2 as a putative BMP4 downstream gene for eye devel opment, however, awai ts future genetic studies. For example, Msx2 may regul ate expression of other signal ing mol ecules involved in lens induction (Fig. 9).

BMP4 may be one of the signals among multiple inductive influences from the optic vesicle

An alternative mechanism by which BM P4 may regulate lens induction is by acting synergistically with addi- 


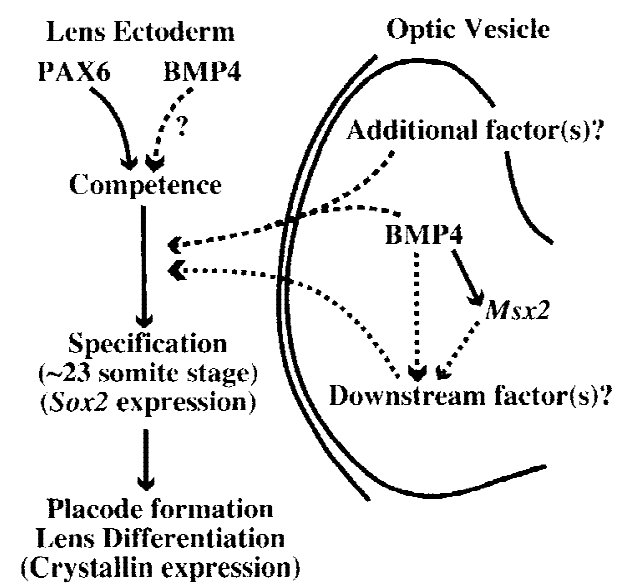

Figure 9. A model for the possible roles of BM P4 during determination of the lens ectoderm. BM P4 may induce the optic vesicle factor(s) (downstream factors) that serve(s) as the signal (s) for lens induction. Transcription factors, such as MSX2, encoded by putative BMP4 downstream genes, may regulate expression of such optic vesicle factor(s). Alternatively, or in addition, BMP4 itself may function as a part of the inductive signal in synergy with other secreted factors (additional factors). PAX6 function in the ectoderm is essential for establishment of the competence to respond to the optic vesiclesignal, and BM P4 may also be required independently from Pax6 for this process.

tional factor(s) expressed in the optic vesicle (Fig. 9). In fact, in tissue recombination experiments using wildtype ectoderm cultured with mutant optic rudiment, we observe lentoid formation in the ectoderm, although at a low frequency (Fig. 7E,F; Table 4). This result suggests that if the ectoderm has been exposed to BM P4 and/or BM P4-dependent signals to some extent before recombination, the ectoderm can form a lens in response to the inductive signal from the optic vesicle, even in the absence of BM P4. This may suggest that additional factors other than BM P4 in the optic vesicle are al so involved in the inductive influence of the optic vesicle (Fig. 9).

In Drosophila, different classes of signal ing molecules, including decapentaplegic, hedgehog, and wingless, have been implicated in eye development, and are known to cooperate one another (Chanut and Heberlein 1997; Dominiguez and Haufen 1997; Royet and Finkelstein 1997). To date, however, there is no evidence that the vertebrate Wnts and $\mathrm{Hhs}$ are expressed in the distal optic vesicle at the stages of lens induction. A nother BMP family member, Bmp7, is expressed in the early developing eye, in areas partially overlapping with those of Bmp4 (Dudley and Robertson 1997; al so cf. Figs. 2D and 3G). Targeted mutation of this gene causes abnormal ity in eye development (Dudley et al. 1995; Luo et al. 1995). Expression of Bmp7 appears unaffected in the $\mathrm{Bmp}^{\mathrm{tm}}{ }^{\mathrm{m}}$ mutant eye (Fig. 3G, K), excluding the possi bility that the lens induction defect in $\mathrm{Bmp}^{\mathrm{tm} 1}$ mutant embryos is attributable to additional loss of Bmp7 expression. In addition, homodimeric BM P4 protein is sufficient to rescue lens induction in $\mathrm{Bmp}^{\mathrm{tm}}{ }^{1}$ mutant embryos. Elucidating the possible synergistic functions of these BM Ps and/or the requirement for heterodi mers in lens induction in vivo awaits more detailed characterization of lens induction defects in Bmp7 mutant embryos, and the generation of compound mutants for these genes.

Fibroblast growth factors (FGFs) are another family of secreted signaling molecules that have been relatively well-studied in relation to vertebrate lens development (Robinson et al. 1995; Stolen et al. 1997). Although FGFs function antagonistically to BMPs in some developing organs ( $\mathrm{N}$ iswander and $\mathrm{M}$ artin 1993; N eubuser et al. 1997), they appear to act synergistically in others (Lough et al. 1996; Ericson et al. 1998). To our knowledge, FGF1 and FGF15 are the only members of FGFs known to be expressed in the eye before lens placode formation. $\mathrm{Be}$ cause FGF1 is expressed only in the presumptive lens ectoderm at the time of lens induction, but not in the optic vesicle (de lough et al. 1993), it is unlikely that FGF1 mediates inductive influence of the optic vesicle. FGF15 is a relatively newly identified member of this family, and the predicted amino acid sequence suggests its secreted nature (M cWhirter et al. 1997). The activity of FGF15 in lens induction and the possibility of synergistic action between FGF15 and BM P4 will be studied in the future using biologically active protein and/or expression systems.

BMP4 may also be required for the lens ectoderm to respond to the optic vesicle signal

The current model for lens induction suggests that the prospective lens ectoderm is determined in a stepwise manner (for review, see Grainger 1992). At the late gastrula to early neurula stages of amphibian embryos, a planar signal from the anterior neural plate is thought to have a critical role for induction of the lens ectoderm. It has al so been shown that the dorsolateral mesoderm of the future cardiac regi on underlying the prospective lens ectoderm appears to enhance this inductive process (Henry and Grainger 1990). These inductive signal s have, however, not been characterized at the molecular level.

The mesoderm of the future cardiac region is one of the early expression domains of Bmp4 during embryonic devel opment (Y. Furuta and B.L.M . Hogan, unpubl.; al so see Schultheiss et al. 1997). We also report here that Bmp4 transcripts are present transiently in the presumptive lens ectoderm (Fig. 2B-D). Furthermore, one of the BM P receptor genes, Alk3, is expressed ubiquitously, including in the ectoderm from early stages of development (Fig. 3G-J; Dewulf et al. 1995; M ishina et al. 1995). Therefore, it is likely that the ectoderm has al ready been exposed to the BM P4 signal before it contacts the optic vesicle. These observations suggest that BM P4 also has a role in earlier steps of determination of the presumptive lens ectoderm (Fig. 9).

Tissue recombination experiments using rSey mutant embryos revealed that PAX6 participates in the establishment of lens competence in the head ectoderm. Expression of Pax6 does not appear to be changed in $\mathrm{Bmp}^{\mathrm{tm} 1}$ mutant embryos (Fig. $3 \mathrm{E}, \mathrm{I}$ ), and expression of 
genes encoding BM P4 and its receptors appear unaffected in the eye of Pax6 $6^{\mathrm{Sey}-1 \mathrm{Neu}}$ mutant embryos (Fig. 8). Therefore, if BMP4 functions in the establishment of lens competence in the ectoderm, it may be involved in a different pathway from that of PAX6 (Fig. 9).

Given that BMP4 is a secreted molecule, there are technical limitations to elucidating its functions separately in the ectoderm and optic vesicle using tissue recombination experiments with $\mathrm{Bmp}^{\mathrm{tm} 1}$ mutant embryos. In future investigations, this issue must be addressed by blocking BMP4 signaling in a cell-type specific manner during lens induction. Similar approaches to inactive BM P4 or BM P receptor functions in a stage-specific manner in the developing eye will also all ow us to study the role of BM P4 during later stages of eye development, as well as during the lens induction process.

\section{Materials and methods}

\section{Mice}

Embryos from ICR mice (Harlan Sprague-Dawley, Indianapolis) were used as wild-type samples. Heterozygous Bmp4 $4^{\mathrm{tm} 1}$ mutant mice (Winnier et al. 1995) have been maintained on a mixed outbred genetic background (129/SvEv $\times$ Black Swiss). Heterozygous Pax6 $6^{\text {Sey-1Neu }}$ mice have been maintained by backcrossing with ICR (Grindley et al. 1997). In tissue recombination experiments, embryos obtained from crosses between ICR females and homozygous mal es of the ROSA26 strain (Zambrowicz et al. 1997) [B6,129-TgR(ROSA 26)26Sor; The Jackson Laboratory, Bar Harbor, ME] were used as wild-type samples. $\mathrm{N}$ oon of the day of the vaginal plug is $0.5 \mathrm{dpc}$.

\section{Tissue preparations for histological analyses}

Embryos or cultured explants were fixed in 4\% paraformaldehyde in PBS, dehydrated through a graded series of methanol, and embedded in wax (Paraplast Plus, Fischer Scientific) for histological sectioning. Sections were processed for hematoxylin and eosin staining, in situ hybridization, or immunohistochemistry (see below).

In situ hybridization and histochemical analyses

In situ hybridization using $\left[{ }^{35} \mathrm{~S}\right] \mathrm{UTP}$-label ed riboprobes on sections was performed essentially as described (Hogan et al. 1994). The Bmp4, Msx2, Bf1, Bf2, Bmp7, Otx2, Alk3 (BmprlA), Six3, Eya1, Eya2, Pax6, and Sox2 probes have been described previously (Jones et al. 1991; M onaghan et al. 1991; Hatini et al. 1994; Lyons et al. 1995; M atsuo et al. 1995; M ishina et al. 1995; Oliver et al. 1995; Grindley et al. 1997; Xu et al. 1997; Kamachi et al. 1998). The Alk6 (BmprlB) probe was kindly provided by Dr. Lee $\mathrm{N}$ iswander (Sloan-Kettering Institute, N ew York, NY). Pictures were taken by double exposures, using a red filter for the dark field, and a blue filter for the bright field illuminations. A rabbit antiserum raised against rat $\alpha \mathrm{A}$-crystallin (kind gift from $\mathrm{Dr}$. Kanefusa Kato; Kato et al. 1991) was used as the primary antibody for immunohistochemical detection of lens differentiation. Secondary antibody was an anti-rabbit IgG antibody (goat) conjugated with biotin (Jackson ImmunoResearch Laboratories; Cat.\#111-066-003), to which peroxidase-conjugated streptoavidin (Vectastain ABC kit; Vector Laboratories) was then bound.
The immuno-enzyme complex was detected by a color reaction using diaminobenzidine $(0.6 \mathrm{mg} / \mathrm{ml}$ in $50 \mathrm{~mm}$ Tris- $\mathrm{Cl}, \mathrm{pH} 7.6)$ as a chromogenic substrate in the presence of $0.03 \% \mathrm{H}_{2} \mathrm{O}_{2}$. $\mathrm{He}$ matoxylin was used for counterstaining. Assay for $\beta$-galactosidase ( $\beta-G$ al ) activity in the explants was performed as described (Hogan et al. 1994), and stained samples were processed for sectioning as described above, and then counterstained with eosin.

\section{Explants and recombinations of embryonic eye tissues}

Organ culture using filters was performed essentially as described (Furuta et al. 1997). For surgical removal of the optic vesicle, bead transplantation, and tissue recombination, the heads of 8.75-9.0 dpc wild-type or $9.75-10.0 \mathrm{dpc} B m p 4^{\mathrm{tm} 1}$ homozygous mutant embryos were isolated, and treated with pancreatin-trypsin (Hogan et al. 1994) for $5 \mathrm{~min}$. on ice, and the ectoderm was dissociated from the underlying optic vesicle and mesenchyme (optic rudiment). With this treatment, we could not completely avoid contamination of a small population of the head mesenchyme attached to the ectoderm, as longer treatment substantially damaged the tissues. The optic vesicle was then removed, or replaced with tissues or beads, and the ectoderm was put back again. For tissue recombinations, isolated ectoderm was put onto an optic rudiment from another embryo. In most cases, one side of the eye was used for manipulations, while the other retained as an unmanipulated control. After manipulation, tissues were incubated for $1-2 \mathrm{hr}$ on a pad of agar containing culture medium to allow the ectoderm to adhere to the underlying tissues. $M$ anipulated samples were cut al ong the midline into halves, and then transferred onto the filter with the ectoderm facing up. For application of proteins, carrier beads were prepared as previously described (Furuta et al. 1997). For implantation of beads into the optic vesicle, one side of the eye was incubated with BM P4-carrying beads, and the other with control BSA beads. The concentration of recombinant human BM P4 (kindly provided by the Genetics Institute, Cambridge, MA) used for preparation of protein carrying beads was 1-5 $\mu \mathrm{g} /$ $\mathrm{ml}$.

\section{Acknowledgments}

We thank Miss Lorene Batts for technical assistance; Drs. D. Greenstein, M. Gannon, S. Kidson, L. Liaw, G. Oliver, and colleagues of the Hogan laboratory for critical reading of the manuscript; and Drs. Y. Kamachi and H. Kondoh for hel pful discussions. We are also grateful to Drs. S. Aizawa, R. Hill, K. Kato, H. Kondoh, E. Lai, R. Maas, Y. Mishina, L. Niswander, and G. Oliver for providing us with reagents. Y.F. was a Research Associate, and B.L.M.H. is an Investigator of Howard Hughes Medical Institute.

The publication costs of this article were defrayed in part by payment of page charges. This article must therefore be hereby marked 'advertisement' in accordance with 18 USC section 1734 solely to indicate this fact.

\section{References}

Chanut, F. and U. Heberlein. 1997. Role of decapentaplegic in initiation and progression of the morphogenetic furrow in the developing Drosophila retina. Development 124: 559567.

de longh, R., F.J. Lovicu, A. Hanneken, and J.W. M cAvoy. 1993. Spatio-temporal distribution of acidic and basic FGF indicates a role for FGF in rat lens morphogenesis. Dev. Dyn. 
198: 190-202.

Dewulf, N., K. Verschueren, O. Lonnoy, A. M oren, S. Grimsby, K. Vande Spiegle, K. M iyazono, D. Huylebroeck, and P. Ten Dijke, P. 1995. Distinct spatial and temporal expression patterns of two type I receptors for bone morphogenetic proteins during mouse embryogenesis. Endocrinology 136: 2652-2663.

Dominguez, M. and E. Hafen. 1997. Hedgehog directly controls initiation and propagation of retinal differentiation in the Drosophila eye. Genes \& Dev. 11: 3254-3264.

Dudley, A.T., K.M. Lyons, and E.J. Robertson. 1995. A requirement for bone morphogenetic protein-7 during development of the mammalian kidney and eye. Genes \& Dev. 9: 27952807.

Dudley, A.T. and E.J. Robertson. 1997. Overlapping expression domains of bone morphogenetic protein family members potential ly account for limited tissue defects in BM P7 deficient embryos. Dev. Dyn. 208: 349-362.

Ericson, J., S. N orlin, T.M. Jessell, and T. Edlund. 1998. Integrated FGF and BMP signaling controls the progression of progenitor cell differentiation and the emergence of pattern in the embryonic anterior pituitary. Development 125: 1005-1015.

Fujiwara, M., T. Uchida, N. Osumi-Yamashita, and K. Eto. 1994. U chida rat (rSey): A new mutant rat with craniofacial abnormalities resembling those of the mouse Sey mutant. Differentiation 57: 31-38.

Furuta, Y., D.W. Piston, and B.L.M. Hogan. 1997. Bone morphogenetic proteins (BM Ps) as regulators of dorsal forebrain de velopment. Development 124: 2203-2212.

Glaser, T., L. Jepeal, J.G. Edwards, S.R. Y oung, J. Favor, and R.L. $M$ aas. 1994. PAX6 gene dosage effect in a family with congenital cataracts, aniridia, anophthal mia and central nervous system defects. Nature Genet. 7: 463-471.

Grainger, R.M., J.J. Herry, and R.A. Henderson. 1988. Reinvestigation of the role of the optic vesicle in embryonic lens induction. Development 102: 517-526.

Grainger, R.M. 1992. Embryonic lens induction: shedding light on vertebrate tissue determination. Trends Genet. 8: 349355.

Graw, J. 1996. Genetic aspects of embryonic eye devel opment in vertebrates. Dev. Genet. 18: 181-197.

Grindley, J.C., L,K. Hargett, R.E. Hill, A. Ross, and B.L.M. Hogan. 1997. Disruption of PAX6 function in mice homozygous for the Pax6 $6^{\text {Sey-1 neu }}$ mutation produces abnormal ities in the early development and regionalization of the diencephalin. Mech. Dev. 64: 111-126.

Hanson, I.M., J.M. Fletcher, T. Jordan, A. Brown, D. Taylor, R.J. Adams, H.H. Punnett, and V. van Heyningen. 1994. Mutations at the PAX 6 locus are found in heterogeneous anterior segment malformations including Peters' anomaly. Nat. Genet. 6: 168-173.

Hatini, V., W. Tao, and E. Lai. 1994. Expression of winged helix genes, BF-1 and BF-2, define adjacent domains within the devel oping forebrain and retina. J. Neurobiol. 25: 1293-1309.

Henry, J.J. and R.M. Grainger. 1990. Early tissue interactions leading to embryonic lens formation in Xenopus laevis. Dev. Biol. 141: 149-163.

Hill, R.E., J. Favor, B.L.M. Hogan, C.C.T. Ton, G.F. Saunders, I.M. Hanson, J. Prosser, T. Jordon, N.D. Hastie, and V. van Heyningen. 1991. M ouse Small eye results from mutations in a paired-like homeobox-containing gene. Nature 354: 522-525.

Hogan, B., R. Beddington, F. Costantini, and E. Lacy. 1994. Manipulating the mouse embryo; A laboratory manual. Cold Spring Harbor Laboratory Press, Cold Spring Harbor, N ew
York.

Hogan, B.L.M. 1996. Bone morphogenetic proteins: Multifunctional regulators of embryonic development. Genes \& Dev. 10: 1580-1594.

Jacobson, A.G. and A.K. Sater. 1988. Features of embryonic induction. Development 104: 341-359.

Jones, C.M., K.M. Lyons, and B.L.M. Hogan. 1991. Involvement of bone morphogenetic protein-4 (BM P-4) and Vgr-1 in morphogenesis and neurogenesis in the mouse. Development 111: $531-542$.

Jordan, T., I.M. Hanson, D. Zal etayev, S. Hodgson, J. Prosser, A. Seawright, N.D. Hastie, and V. van Heyningen. 1992. The human PAX 6 gene is mutated in two patients with anididia. Nat. Genet. 1: 328-332.

Kamachi, Y., S. Sockanathan, Q. Liu, M. Breitman, R. LovellBadge, and H. Kondoh. 1995. Involvement of SOX proteins in lens-specific activation of crystallin genes. EMBO J. 14: 3510-3519.

Kamachi, Y., M. U chikawa, J. Collignon, R. Lovell-Badge, and H. Kondoh. 1998. Involvement of Sox1, 2, and 3 in the early and subsequent molecular events of lens induction. Development 125: 2521-2532.

Kato, K., H. Shinohara, N. Kurobe, S. Goto, Y. Inaguma, and K. Ohshima. 1991. Immunoreactive aA crystallin in rat nonlenticular tissues detected with a sensitive immunoassay method. BBA 1080: 173-180.

Kaufman, M.H. 1994. The atlas of mouse development. Academic Press, San Diego, CA.

Lewis, W.H. 1904. Experimental studies on the development of the eye in Amphibia. I. On the origin of the lens, Rana palustris. Am. J. Anat. 3: 505-536.

-_- 1907a. Experimental studies on the development of the eye in Amphibia. III. On the origin and differentiation of the lens, Rana palustris. Am. J. Anat. 6: 473-509.

- - - 1907b. Lens formation in strange ectoderm in Rana sylvatica. Am. J. Anat. 7: 145-169.

Li, H.-S., J.-M. Yang, R.D. Jacobson, and D.P.O. Sundin. 1994. Pax6 is first expressed in a region of ectoderm anterior to the early neural plate: Implications for stepwise determination of the lens. Dev. Biol. 162: 181-194.

Lough, J., M. Barron, M. Brogley, Y. Sugi, D.L. Bolender, and X. Zhu. 1996. Combined BM P-2 and FGF-4, but neither factor alone, induces cardiogenesis in non-precardiac embryonic mesoderm. Dev. Biol. 178: 198-202.

Luo, G., C. Hofmann, A.L. Bronckers, M. Sohocki, A. Bradley, and G. Karsenty. 1995. BM P-7 is an inducer of nephrogenesis, and is also required for eye development and skel etal patterning. Genes \& Dev. 9: 2808-2820.

Lyons, K.M., B.L.M. Hogan, and E.J. Robertson. 1995. Colocalization of BM P 7 and BM P 2 RN As suggest that these factors cooperatively mediate tissue interactions during murine development. Mech. Dev. 50: 71-83.

Matsuo, T., N. Osumi-Yamashita, S. Noji, H. Ohuchi, E. Koyama, F. Myokai, N. Matsuo, S. Taniguchi, H. Doi, S. Iseki, and K. Etoh. 1993. A mutation in the Pax-6 gene in rat small eye is associated with impaired migration of midbrain crest cells. Nat. Genet. 3: 299-304.

Matsuo, I., S. Kuratani, C. Kimura, N. Takeda, and S. Aizawa. 1995. M ouse Otx2 functions in the formation and patterning of rostral head. Genes \& Dev. 9: 2646-2658.

McWhirter, J.R., M. Goulding, J.A. Weiner, J. Chun, and C. Murre. 1997. A novel fibroblast growth factor gene expressed in the developing nervous system is a downstream target of the chimeric homeodomain oncoprotein E2A-Pbx1. Development 124: 3221-3232.

Mishina, Y., A. Suzuki, N. Ueno, and R.R. Behringer. 1995. 
Bmpr encodes a type I bone morphogenetic protein receptor that is essential for gastruolation during mouse embryogenesis. Genes \& Dev. 9: 3027-3037.

Monaghan, A.P., D.R. Davidson, C. Sime, E. Graham, R. Baldock, S.S. Bhattacharya, and R.E. Hill. 1991. The M sh-like homeobox genes define domains in the developing vertebrate eye. Development 112: 1053-1061.

N eubuser, A., H. Peters, R. Balling, and G. Martin. 1997. Antagonistic interactions between FGF and BMP signaling pathways: A mechanism for positioning the sites of tooth formation. Cell 90: 247-256.

Niswander, L. and G.R. Martin. 1993. FGF-4 and BMP-2 have opposite effects on limb growth. Nature 361: 68-71.

Oliver, G., A. Mailhos, R. Wehr, N.G. Copeland, N.A. Jenkins, and P. Gruss. 1995. Six3, a murine homologue of the sine oculis gene, demarcates the most anterior border of the developing neural plate and is expressed during eye development. Development 121: 4045-4055.

Oliver, G. and P. Gruss. 1997. Current views on eye development. Trends Neurosci. 20: 415-421.

Porter, F.D., J. Drago, Y. Xu, S.S. Cheema, C. Wassif, S.P. Huang, E. Lee, A. Grinberg, J.S. M assalas, D. Bodine, F. Alt, and H. Westphal. 1997. Lhx2, a LIM homeobox gene, is required for eye, forebrain, and definitive erythrocyte development. Development 124: 2935-2944.

Robinson, M.L., L.A. MacMillan-Crow, J.A. Thompson, and P.A. Overbeek. 1995. Expression of a truncated FGF receptor results in defective lens development in transgenic mice. Development 121: 3959-3967.

Royet, J. and R. Finkel stein. 1997. Establishing primordia in the Drosophila eye-antennal imaginal disc: The roles of decapentaplegic, wingless, and hedgehog. Development 124: 4793-4800

Saha, M.S., C.L. Spann, and R.M. Grainger. 1989. Embryonic lens induction: More than meets the optic vesicle. Cell Diff. Dev. 28: 153-171.

Schultheiss, T.M., J.B. Burch, and A.B. Lassar. 1997. A role for bone morphogenetic proteins in the induction of cardiac myogenesis. Genes \& Dev. 11: 451-462.

Spemann, H. 1901. Uber korrelation in der entwicklung des auges. Verh. A nat. Ges. 15: 61-79.

Stolen, C.M., M.W. Jackson, and A.E. Griep. 1997. Overexpression of FGF-2 modulates fiber cell differentiation and survival in the mouse lens. Development 124: 4009-4017.

ten Dijke, P., H. Yamashita, H. Ichijo, P. Franzen, M. Laiho, K. Miyazono, and C.-H. Heldin. 1994. Identification of type I receptors for osteogenic protein-1 and bone morphogenetic protein-4. J. Biol. Chem. 269: 16985-16988.

Winnier, G., M. Blessing, P.A. Labosky, and B.L.M. Hogan. 1995. Bone morphogenetic protein-4 is required for mesoderm formation and patterning in the mouse. Genes \& Dev. 9: 2105-2116.

Xu, P.X., I. Woo, H. Her, D.R. Beier, and R.L. M aas. 1997. M ouse Eya homologues of the Drosophila eyes absent gene require Pax6 for expression in lens and nasal placode. Development 124: 219-231.

Zambrowicz, B.P., A. Imamoto, S. Fiering, L.A. Herzenberg W.G. Kerr, and P. Soriano. 1997. Disruption of overlapping transcripts in the ROSA $\beta$ geo 26 gene trap strain leads to widespread expression of $\beta$-galactosidase in mouse embryos and hematopoietic cells. Proc. Natl. Acad. Sci. 94: 3789-3794. 


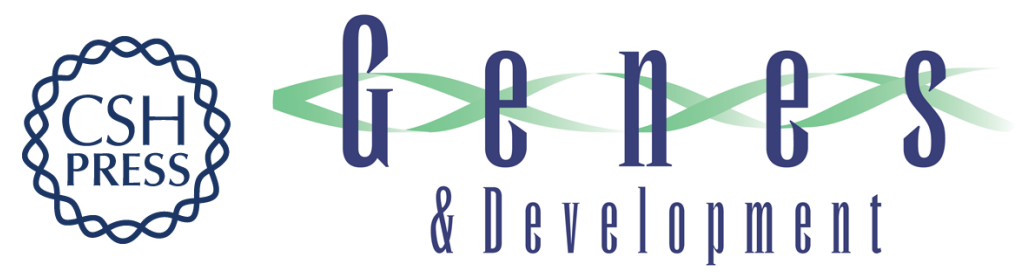

\section{BMP4 is essential for lens induction in the mouse embryo}

Yasuhide Furuta and Brigid L.M. Hogan

Genes Dev. 1998, 12:

Access the most recent version at doi:10.1101/gad.12.23.3764

References This article cites 51 articles, 25 of which can be accessed free at: http://genesdev.cshlp.org/content/12/23/3764.full.html\#ref-list-1

License

Email Alerting Receive free email alerts when new articles cite this article - sign up in the box at the top Service right corner of the article or click here.

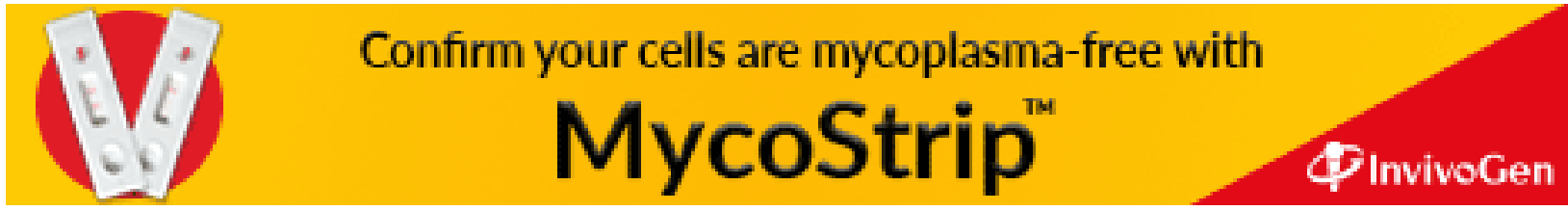

